\title{
Removal of Less Volatile Impurities from Crude Indium by Vacuum
}

\section{Distillation}

\author{
Yong Deng ${ }^{1, a}$ Dongsheng $\mathrm{Li}^{2}$ Zhang Dingchuan ${ }^{1,2}$ Heng Xiong $^{2}$ \\ ${ }^{1} 1$ Key Laboratory for Nonferrous Vacuum Metallurgy of Yunnan Province, Kunming 650093, China \\ ${ }^{2}$ Faculty of Metallurgical and Energy Engineering, Kunming University of Science and Technology, \\ Kunming University of Science and Technology, Kunming 650093, China \\ a dengxinnuo@126.com
}

Keywords: Crude Indium; Less Volatile Impurities; Purification; Saturated Vapor Pressure; Vacuum Distillation.

Abstract: The less volatile impurities has been eliminated by high temperature vacuum distillation of crude indium. The experiment was carried out in a self-designed vacuum distillation furnace. The temperature of distillation experiment was carried out at $1273 \sim 1373 \mathrm{~K}$ and samples of condensate were collected at time intervals of 2, 3, 4 and 5 hour.The content of $\mathrm{Ni}, \mathrm{Cu}, \mathrm{Fe}$ in the crude indium have a little changed with the distillation time extension or the distillation temperature ascension. Both distillation temperature and holding time are principal factors that affected the removal of $\mathrm{Sn}$ from In by vacuum distillation. Compared with distillation time, temperature on the removal of less volatile impurities effects is more significant, So the distillation temperature was more important than distillation time. The best conditions of removal of less volatile impurities from crude indium under dynamic vacuum of $1 \sim 5 \mathrm{~Pa}$ were as follows: $1348 \mathrm{~K}$ and $2 \mathrm{~h}$. Under this condition, the content of impurities could be reduce to the standard of $5 \mathrm{~N}$ such as $\mathrm{Sn} 、 \mathrm{Cu} 、 \mathrm{Fe} 、 \mathrm{Ni}$ in the crude indium that have high boiling point. The ELEMENT-GD have been used in testing the element contents of the samples.

\section{Introduction}

Indium is applied to the lot of industrial products. As a strategic electronic material, high purity indium was used in electrical industries due to the excellent mechanical, physical and chemical performance. And it is extensively used in semiconductors, the manufacture of liquid crystal displays, infrared photodetectors and low-temperature solders ${ }^{[1]}$. By creating deep energy levels, the residual impurities even in less than ppm level concentration play a major role in the electronic properties. So these industrial products demand high purity indium metal. There are several methods can prepare high purity indium such as electro-refining ${ }^{[2]}$, vacuum distillation ${ }^{[3]}$, low halide, the thin layer fused wall and zone refining ${ }^{[4]}$, etc. In early research, the preparation of high purity indium metal by two-step vacuum distillation method has been studied ${ }^{[5-9]}$. There are two factors such as distillation temperature and distillation time affecting the average content of impurity elements in the crude indium in the two-step vacuum distillation process. Two-step process are low temperature distillation and high temperature distillation. The low temperature distillation is the step one and the high temperature distillation is the step two. In the low temperature distillation step high vapour pressure impurities were carried out at a comparatively lower temperature under a dynamic vacuum, such as $\mathrm{Zn}, \mathrm{Cd}, \mathrm{Tl}, \mathrm{Pb}$. In this stage, $\mathrm{Zn}, \mathrm{Cd}, \mathrm{Tl}, \mathrm{Pb}$ were collected on the condenser and less volatile impurities were left over in the bottom of the crucible. In the second step 
less volatile impurities were removed at a comparatively higher temperature under a dynamic vacuum. In this stage, $\mathrm{Sn}, \mathrm{Fe}, \mathrm{Cu}, \mathrm{Ni}$ were left over in the bottom of the crucible and the indium was collected on the condenser. It found that the purification of the crude indium was very good by two vacuum distillation purification, except low boiling point impurities. Why is this so hard? The pollution in the process of distillation equipment was probably the main reason through the analysis of the experiment. Therefore the prophase vacuum distillation process will be changed: high temperature distillation will take place in the first phase and then to low temperature distillation. In this paper removal of less volatile impurities from the crude indium in the first phase was studied. The ELEMENT-GD produced by Thermo Scientific Company is one of the most advanced analysis equipment for detection the high-purity metals. It have been used in testing the element contents of the samples with its accuracy up to $10^{-9}(\mathrm{ppb})$.

\section{Experimental}

The distillation was carried out in a self-designed vacuum furnace system which consists of an resistance heated vacuum furnace, rotary-vane pump and temperature controlling system. The temperature controlling system is made up of thermocouple, temperature instrument and electrical source controller. The resistance heated vacuum furnace is made up of heating element, crucible, electrode and condenser. The schematic details of resistance heated vacuum furnace are shown in Fig.1. In order to change of condensation strength the condenser can be moved up and down. The content of indium as raw material is listed in Table 1 ( Indium content is 99.7\%).

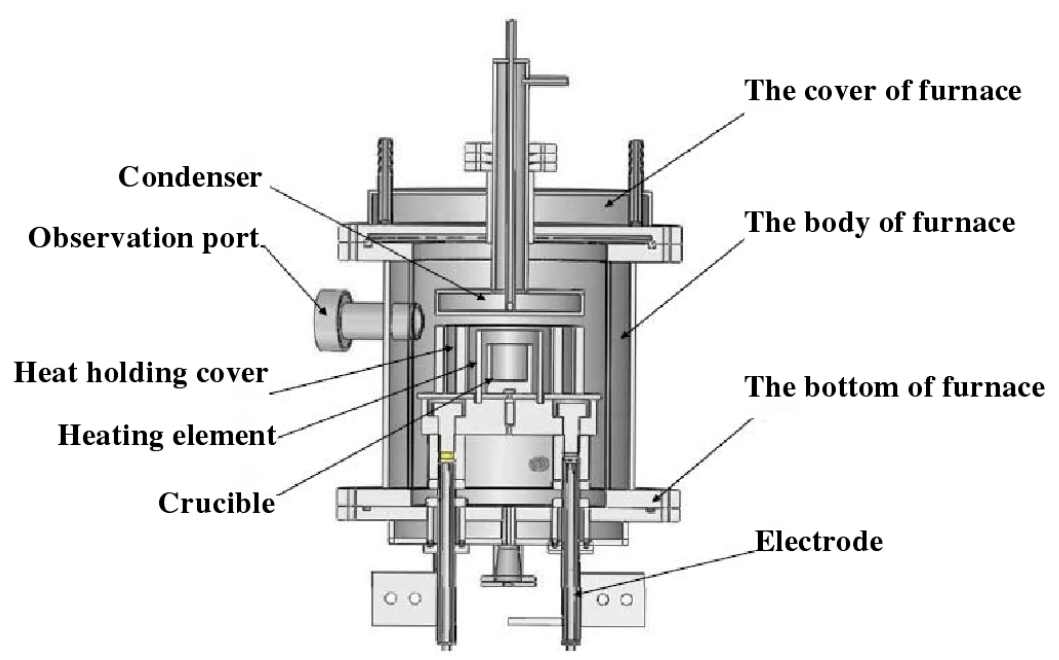

Fig.1 The resistance heated vacuum furnace

Table 1 The content of indium (all values in $\mathrm{ppm}$ )

\begin{tabular}{ccccccccccccccc}
\hline Element & $\mathrm{Sn}$ & $\mathrm{Fe}$ & $\mathrm{Cu}$ & $\mathrm{Ni}$ & $\mathrm{Cd}$ & $\mathrm{Zn}$ & $\mathrm{Tl}$ & $\mathrm{Pb}$ & $\mathrm{S}$ & $\mathrm{As}$ & $\mathrm{Al}$ & $\mathrm{Ag}$ & $\mathrm{Mg}$ & $\mathrm{Si}$ \\
\hline Content & 66.627 & 0.067 & 6.548 & 0.243 & 40.253 & 0.155 & 2848.042 & 49.350 & 3.973 & 0.949 & 0.007 & 0.009 & 0.002 & 0.741 \\
\hline Note : The elements are according to the standard of high indium in worldwide in the table, such as China, USA, Japan, England and Russia.
\end{tabular}

The difference in vapor pressure of each metal at different temperatures was the basic principle of crude metal vacuum distillation ${ }^{[10]}$. The relationships between vapor pressure $(\mathrm{P} / \mathrm{Pa})$ of pure metals in the crude indium and temperature $(\mathrm{T} / \mathrm{K})$ are listed as

$$
\begin{array}{ll}
\lg \mathrm{p}_{\mathrm{Cd}}=-5819 \mathrm{~T}^{-1}-1.257 \operatorname{lgT}+14.412 & (594 \sim 1050 \mathrm{~K}) \\
\lg \mathrm{p}_{\mathrm{Zn}}=-6620 \mathrm{~T}^{-1}-1.255 \mathrm{gT}+14.465 & (692 \sim 1180 \mathrm{~K}) \\
\lg \mathrm{p}_{\mathrm{Tl}}=-9300 \mathrm{~T}^{-1}-0.892 \mathrm{gT}+13.225 & (700 \sim 1800 \mathrm{~K})
\end{array}
$$




$$
\begin{array}{ll}
\lg \mathrm{p}_{\mathrm{Pb}}=-10130 \mathrm{~T}^{-1}-0.985 \lg \mathrm{T}+13.285 & (600 \sim 2023 \mathrm{~K}) \\
\lg \mathrm{p}_{\mathrm{In}}=-12580 \mathrm{~T}^{-1}-0.45 \lg \mathrm{T}+11.915 & (429 \sim 2346 \mathrm{~K}) \\
\lg \mathrm{p}_{\mathrm{Sn}}=-15500 \mathrm{~T}^{-1}+10.355 & (504 \sim 2876 \mathrm{~K}) \\
\lg \mathrm{p}_{\mathrm{Cu}}=-17520 \mathrm{~T}^{-1}-1.21 \lg \mathrm{T}+15.335 & (1357 \sim 2836 \mathrm{~K}) \\
\lg \mathrm{p}_{\mathrm{Fe}}=-19710 \mathrm{~T}^{-1}-1.27 \lg \mathrm{T}+15.395 & (1811 \sim 3135 \mathrm{~K}) \\
\lg \mathrm{p}_{\mathrm{Ni}}=-22400 \mathrm{~T}^{-1}-2.01 \lg \mathrm{T}+19.075 & (1728 \sim 3187 \mathrm{~K})
\end{array}
$$

The saturated vapor pressure of indium and other impurities under different temperatures were calculated. So they are shown in Table 2. From Table 2, it could be seen that $\mathrm{Sn}, \mathrm{Cu}, \mathrm{Fe}, \mathrm{Ni}$ can be removed from the crude indium by high temperature vacuum distillation. They can be left over in the bottom of the crucible and the indium can evaporate into the gas phase. The distillation

\begin{tabular}{|c|c|c|c|c|c|c|c|c|c|}
\hline $\mathrm{T} / \mathrm{K}$ & In & $\mathrm{Tl}$ & $\mathrm{Cd}$ & $\mathrm{Zn}$ & $\mathrm{Pb}$ & Sn & $\mathrm{Fe}$ & $\mathrm{Cu}$ & $\mathrm{Ni}$ \\
\hline 773 & $1.8 \times 10^{-6}$ & $3.6 \times 10^{-2}$ & $1.7 \times 10^{3}$ & $1.7 \times 10^{2}$ & $1.9 \times 10^{-3}$ & $2.0 \times 10^{-10}$ & - & - & - \\
\hline 873 & $3.1 \times 10^{-5}$ & $3.1 \times 10^{-1}$ & $5.4 \times 10^{3}$ & $6.7 \times 10^{2}$ & $1.5 \times 10^{-2}$ & $5.0 \times 10^{-9}$ & - & - & - \\
\hline 973 & $4.3 \times 10^{-3}$ & $9.9 \times 10^{0}$ & $4.7 \times 10^{4}$ & $8.1 \times 10^{3}$ & $8.4 \times 10^{-1}$ & $2.6 \times 10^{-6}$ & - & - & - \\
\hline 1073 & $6.7 \times 10^{-2}$ & $7.1 \times 10^{1}$ & - & $3.1 \times 10^{4}$ & $7.2 \times 10^{0}$ & $8.1 \times 10^{-5}$ & - & - & - \\
\hline 1173 & $6.4 \times 10^{-1}$ & $3.6 \times 10^{2}$ & - & $2.3 \times 10^{5}$ & $4.2 \times 10^{1}$ & $1.4 \times 10^{-3}$ & - & - & - \\
\hline 1273 & $4.3 \times 10^{0}$ & $1.4 \times 10^{3}$ & - & - & $1.8 \times 10^{2}$ & $1.5 \times 10^{-2}$ & - & - & - \\
\hline 1373 & $2.2 \times 10^{1}$ & $4.5 \times 10^{3}$ & - & - & $6.5 \times 10^{2}$ & $1.1 \times 10^{-1}$ & - & $6.1 \times 10^{-2}$ & - \\
\hline 1473 & $8.8 \times 10^{1}$ & $1.2 \times 10^{4}$ & - & - & $1.9 \times 10^{3}$ & $6.8 \times 10^{-1}$ & - & $4.1 \times 10^{-1}$ & - \\
\hline 1573 & $2.9 \times 10^{2}$ & $2.8 \times 10^{4}$ & - & - & $4.9 \times 10^{3}$ & $3.1 \times 10^{0}$ & - & $2.1 \times 10^{0}$ & - \\
\hline 1673 & $8.8 \times 10^{2}$ & $6.1 \times 10^{4}$ & - & - & $1.1 \times 10^{4}$ & $1.2 \times 10^{1}$ & - & $9.2 \times 10^{0}$ & - \\
\hline 1773 & $2.3 \times 10^{3}$ & $1.2 \times 10^{5}$ & - & - & $2.4 \times 10^{4}$ & $4.1 \times 10^{1}$ & - & $3.3 \times 10^{1}$ & $8.1 \times 10^{-1}$ \\
\hline 1873 & $5.3 \times 10^{3}$ & $2.2 \times 10^{5}$ & - & - & $4.5 \times 10^{4}$ & $1.2 \times 10^{2}$ & $5.2 \times 10^{0}$ & $1.0 \times 10^{2}$ & $3.4 \times 10^{0}$ \\
\hline 1973 & $1.1 \times 10^{4}$ & $3.7 \times 10^{5}$ & - & - & $8.0 \times 10^{4}$ & $3.1 \times 10^{2}$ & $1.6 \times 10^{1}$ & $2.9 \times 10^{2}$ & $1.2 \times 10^{1}$ \\
\hline 2073 & $2.3 \times 10^{4}$ & - & - & - & - & $7.5 \times 10^{2}$ & $4.7 \times 10^{1}$ & $7.3 \times 10^{2}$ & $3.9 \times 10^{1}$ \\
\hline
\end{tabular}
temperature should be 1273 1573K under dynamic vacuum of 1 5Pa. Because the amount of impurity elements in the gas phase will increase along with distillation temperatures rising at the same time. The study have used lower temperature and the prolonged distillation time in order better to remove the less volatile impurities. The vacuum distillation experiment was carried out at 1273 1373K: 1273K, 1298K,1323K,1348K,1373K. Samples of condensate were collected at time intervals of 2, 3, 4 and $5 \mathrm{~h}$, in case of high fraction experiment after the melt has attained the respective distillation temperature.

Table 2 Saturation Vapor Pressure of Indium and the Impurity Elements $(\mathrm{Pa})$

*Note: Black part indicated that the vacuum distillation carried out under dynamic vacuum of 1 5Pa.

\section{Results and Discussion}

\section{Calculated the metal evaporation rate}

The influence of temperature and time on the metal evaporation rate was shown in Fig.2. The metal evaporation rate is equal to (weight of the raw material minus weight of the residue) divide by weight of the raw material $\times 100 \%$. Because the content of indium is greater than $99.7 \%$ in the crude indium, it believe that the rate of evaporation metal is equal to the rate of evaporation indium in the distillation process. From Fig.2, it could be seen that distillation time and distillation temperature are the factors influencing indium volatile. The evaporation rate of indium increased along with the distillation temperature ascension or the distillation time extension. At the same distillation time, for example, 3 hour, the evaporation rate of indium was $50.37 \%$ when the distillation temperature has been raised to $1273 \mathrm{~K}$. And the evaporation rate of indium was $99.75 \%$ 
when the distillation temperature has been rised to $1348 \mathrm{~K}$. At the same distillation temperature, for example1323K, the evaporation rate of indium have been raised from $81.35 \%$ to $99.98 \%$ with the distillation time extended from $2 \mathrm{~h}$ to $4 \mathrm{~h}$.

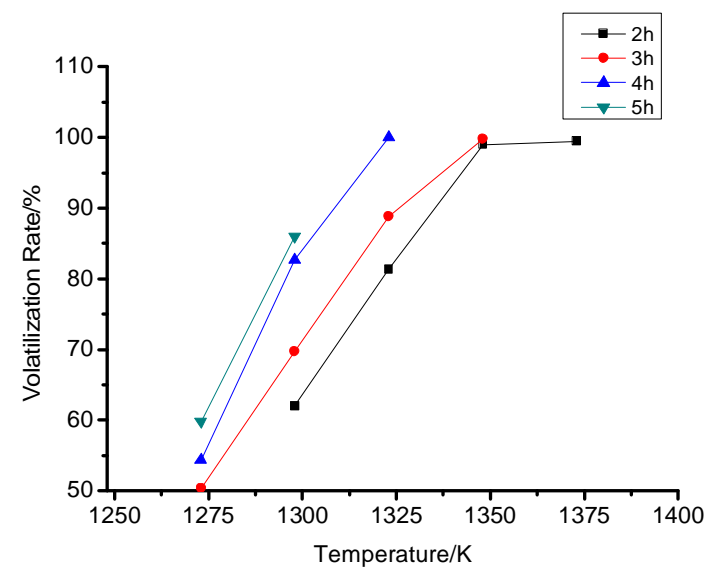

Fig.2. Influence of temperature and time on the metal evaporation rate

*Note: The temperature of the data points from left to right are 1273K,1298K,1323K,1348Kand1373K under dynamic vacuum of 1 5Pa

\section{Behavior of Less Volatile Impurities from Crude Indium}

Distillation at $1273 \sim 1373 \mathrm{~K}$ and a residual gas pressure of $5 \mathrm{~Pa}$, the residue form the distillation - about $1 \%$ of the starting material - contained the less volatile elements, such as $\mathrm{Cu}, \mathrm{Fe}$, $\mathrm{Sn}, \mathrm{Ni}$. The influence of temperature and time on the content of less volatile impurities $(\mathrm{Sn}, \mathrm{Cu}, \mathrm{Ni})$ in the condensate were shown in Fig.3.to Fig.5. From Fig.3, it could be seen that the content of Ni in the crude indium has a little changed with the distillation temperature ascension or the distillation time extension. The content of Ni was less than 0.003. Since the saturated vapor pressure of Ni was 10000 times lower than indium in 1273 1373K. So, there would be little of Ni volatilized along with indium. $\mathrm{Cu}$ and $\mathrm{Fe}$ are identical with $\mathrm{Ni}$ because the saturated vapor pressure of those was 100 times lower than indium in 1273 1373K. It could be seen in Fig.4 that there are a little increased of the content of $\mathrm{Cu}$ in the condensate along with the distillation temperature ascension or the distillation time extension.

From Fig.5, it could be seen that the content of $\mathrm{Sn}$ in the condensate has increased obviously along with the distillation temperature ascension at the same distillation time. There were a large number of volatile of indium when the distillation temperature was more than the boiling point of indium, for example $1273 \mathrm{~K}$. The content of Sn was in the lowest $0.0443 \mathrm{ppm}$ because of Sn was little evaporated in this condition. The $\mathrm{Sn}$ in the solution began to evaporate gradually and condense correspondingly on the condenser together with indium as distillation temperatures continue to rise. The content of $\mathrm{Sn}$ in volatiles increased to $1.165 \mathrm{ppm}$ when the distillation temperature have been raised to $1373 \mathrm{~K}$. So the both distillation temperature and holding time are principal factors that affected the removal of $\mathrm{Sn}$ from the crude indium by vacuum distillation. Compared with distillation time, distillation temperature on the removal of impurity effects is more significant, So the distillation temperature was more important than distillation time. 


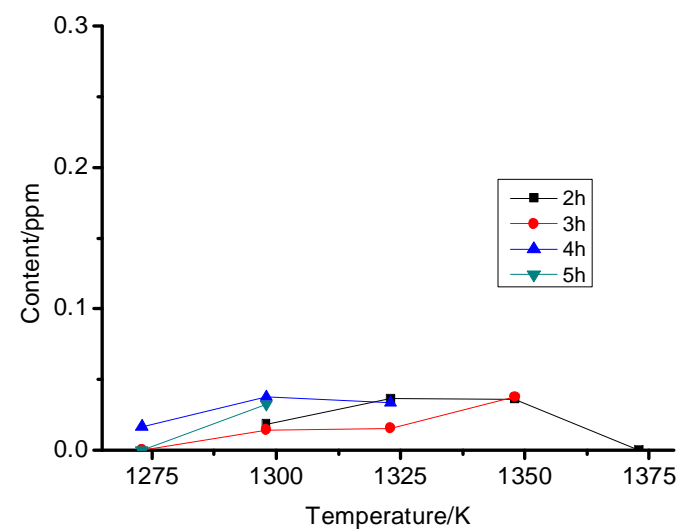

Fig.3. Influence of temperature and time on the content of $\mathrm{Ni}$ in the condensate

*Note: The temperature of the data points from left to right are 1273K,1298K,1323K,1348Kand1373K under dynamic vacuum of 1 5Pa

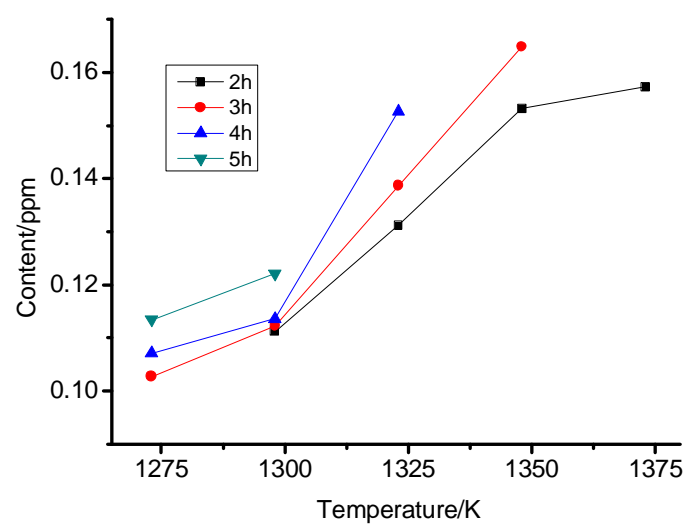

Fig.4. Influence of temperature and time on the content of $\mathrm{Cu}$ in the condensate

*Note: The temperature of the data points from left to right are 1273K,1298K,1323K,1348Kand1373K under dynamic vacuum of 1 5Pa

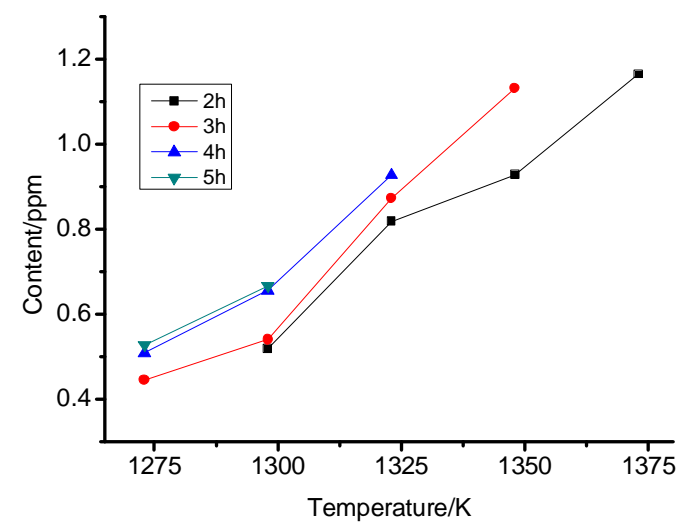

Fig.5. Influence of temperature and time on the content of $\mathrm{Sn}$ in the condensate

*Note: The temperature of the data points from left to right are 1273K,1298K,1323K,1348Kand1373K under dynamic vacuum of $1 \sim 5 \mathrm{~Pa}$

Considering the effect of impurity removal of impurities and the indium metal evaporation rate, the best conditions of removal of less volatile impurities from the crude indium were as follows: distillation temperature for $1348 \mathrm{~K}$, distillation time for $2 \mathrm{~h}$. The content of impurities which have high boiling point namely $\mathrm{Sn}, \mathrm{Cu}, \mathrm{Fe}, \mathrm{Ni}$ in crude indium could be reduce to the standard of $5 \mathrm{~N}$ : the content of $\mathrm{Sn}$ in the condensate is $0.9286 \mathrm{ppm}$, the content of $\mathrm{Cu}$ in the condensate is $0.1532 \mathrm{ppm}$, the content of $\mathrm{Ni}$ in the condensate is $0.357 \mathrm{ppm}$. 


\section{Conclusions}

The vacuum distillation has the low energy consumption, the non-chemical reagent pollution, the gas flows too easy to control and advantages to the environmental protection and other characteristics. The residues and the distillate material are easy to recycle processing by the vacuum distillation processing.

1) The content of $\mathrm{Ni}, \mathrm{Cu}, \mathrm{Fe}$ in the crude indium have a little changed with the distillation temperature ascension or the distillation time extension.

2) Both distillation temperature and holding time are principal factors that affected the removal of $\mathrm{Sn}$ from the crude indium by vacuum distillation. Compared with distillation time, distillation temperature on the removal of impurity effects is more significant, So the distillation temperature was more important than distillation time.

3) The best conditions of removal of less volatile impurities from crude indium under dynamic vacuum of $1 \sim 5 \mathrm{~Pa}$ were as follows: distillation temperature for $1348 \mathrm{~K}$, distillation time for $2 \mathrm{~h}$.

\section{Acknowledgments}

This work was financially supported by Science Research Fundation of Education Department of Yunnan Province.

\section{Reference}

[1] Sami Virolainen, Don Ibana, Erkki Paatero. Recovery of indium from indium tin oxide by solvent extraction, Hydrometallurgy, 2011,107:56-61

[2] Zeng Dongming, Zhou Zhihua, Shu Wangen, Liu Younian and $\mathrm{Hu}$ Aiping. Preparation o f $5 \mathrm{~N}$ high purified indium by the method of chemical purification-electrolysis. Rare $\mathrm{Me}$ ta1s,2002,Jun21(2):137-141

[3] Li Dongsheng, Yang Bin, Dai Yongnian, Deng Yong. Purification of indium up to $5 \mathrm{~N} \mathrm{~b}$ $y$ vacuum distillation[C]. Proceedings of the 10th International Conference on Vacuum Metallurgy and Surface Engineering, Vacuum Engineering Congference 2011 and Vacuu m Consultancy Workshop 2011. Beijing: Publishing House of Eletronics Industry, 2011: 13-19

[4] Zhou Zhihua, Mo Hongbing, Zeng Dongming. Preparation of high-purity indium by elec trolytic refining and zone melting. Rare Metals,28(4) (2004),807-810

[5] Li Dongsheng, Dai Yongnian, Yang Bin, Liu Dachun, Deng Yong. Puriifcation of indi um by vacuum distillation and its analysis [J]. J. Cent. SouthUniv. 2013,20:337-341

[6] Yong Deng, Bin Yang, DongSheng Li, Baoqiang Xu, Heng Xiong. Purification of Indi um by Vacuum Distillation[C]. TMS2013 - the minerals,metals and materials society-mat erials processing fundamentals, 2013: 193-197

[7] Li Dongsheng, Bin Yang, Dai Yongnian, Yong Deng, Baoqiang Xu. Removal of Metal Impurities from Crude Indium by Vacuum Distillation[J], Chinese Journal of Vacuum Science and Technology, 2012,32(4): 176-179

[8] Deng Yong, Yang Bin, Liu Dachun, Xu Baoqiang. Preparation Technology and Applicati on of High-Purity Indium[J]. Chinese Journal of Rare Metals. 2006,30(8):78-81

[9] DU Guoshan YANG Bin DAI Yongnian. Removal of $\mathrm{Cd}, \mathrm{Zn}, \mathrm{Tl}$ and $\mathrm{Pb}$ from Indium by Vacuum Distillation [J]. Yunnan Chemical Technology. 2006,6(33):28-31

[10] Dai Yongnian, Yang Bin. Vaccum metallurgy of Nonferrous metal materials[M]. Beijin: Metallurgical industry Press.2000 